\title{
IMPLIKASI PASANG-SURUTNYA DUKUNGAN \\ TERHADAP WARISAN BUDAYA DUNIA SUBAK JATILUWIH TABANAN, BALI
}

\author{
I Gede Susila \\ Email: ochakiswara6@gmail.com
}

\begin{abstract}
Subak Jatiluwih's choice for World Cultural Heritage must be based on the conservation of nature and culture because of traditional social organization. It means that Subak Jatiluwih's choice for World Cultural Heritage has strong support from various stakeholders, as well as the community, government, and UNESCO. Support for preserving Subak Jatiluwih as World Cultural Heritage must remain strong, as the main objective of the World Cultural Heritage site selection is the preservation of the site itself. But the first support for the preservation of Subak Jatiluwih is very strong and then gradually getting weaker.

The purpose of this research is to know and understand as well as explain the implications of the ups and downs of the support of stakeholders towards the preservation of the natural environment and local culture in Subak Jatiluwih as WBD, both in the life of the stakeholders and the management of the Subak area as world cultural heritage.

The implementation of this research used qualitative research methods and four theories, namely the theory of human ecology, sociocultural theory, theory of deconstruction, and practical theory. The results showed that the ups and downs of support for WBD Subak Jatiluwih implied important things to be criticized. The implications are: (1) the occurrence of top-down policies in proposing Subak Jatiluwih to be WBD and in its management after becoming WBD; (2) there is a process of internationalization or globalization of Subak Jatiluwih to become more famous throughout the world.
\end{abstract}

Keywords: Nature and Culture Conservation, World Cultural Heritage, Subak, Local Ideology, Global Ideology.

\begin{abstract}
Abstrak
Pilihan Subak Jatiluwih untuk Warisan Budaya Dunia (WBD) harus didasarkan pada konservasi alam dan budaya karena organisasi sosial tradisional. Ini berarti bahwa pilihan Subak Jatiluwih untuk Warisan Budaya Dunia memiliki dukungan kuat dari berbagai pemangku kepentingan, masyarakat, pemerintah dan UNESCO. Dukungan untuk
\end{abstract}


melestarikan Subak Jatiluwih sebagai Warisan Budaya Dunia harus tetap kuat, karena tujuan utama pemilihan situs Warisan Budaya Dunia adalah pelestarian situs itu sendiri. Namun dukungan pertama untuk pelestarian Subak Jatiluwih sangat kuat dan kemudian secara bertahap menjadi lebih lemah.

Tujuan dari penelitian ini adalah untuk mengetahui dan memahami serta menjelaskan implikasi dari naik turunnya dukungan dari para pemangku kepentingan terhadap pelestarian lingkungan alam dan budaya lokal di Subak Jatiluwih sebagai Warisan Budaya Dunia (WBD), baik dalam kehidupan para pemangku kepentingan dan dalam pengelolaan kawasan subak sebagai warisan budaya dunia.

Dalam pelaksanaan penelitian ini digunakan metode penelitian kualitatif dan empat teori, yaitu teori ekologi manusia, teori sosiokultural, teori dekonstruksi, dan teori praktis. Hasil penelitian menunjukkan bahwa naik turunnya dukungan untuk WBD Subak Jatiluwih menyiratkan hal-hal penting untuk dikritik. Implikasinya adalah: (1) terjadinya kebijakan top down dalam mengusulkan Subak Jatiluwih menjadi WBD dan dalam manajemennya setelah menjadi WBD; (2) ada proses internasionalisasi Subak Jatiluwih untuk menjadi lebih terkenal di seluruh dunia.

Kata Kunci: Konservasi Alam dan Budaya, Warisan Budaya Dunia, Subak, Ideologi Lokal, Ideologi Global.

\section{Latar Belakang}

Pilihan Subak Jatiluwih untuk Warisan Budaya Dunia (WBD) pastinya berdasarkan pada intensi pelestarian alam dan budaya karena adanya organisasi sosial tradisional. Artinya, pilihan Subak Jatiluwih untuk WBD mendapat dukungan kuat dari berbagai pemangku kepentingan, serta masyarakat, pemerintah dan UNESCO. Dukungan untuk melestarikan Subak Jatiluwih sebagai WBD harus tetap kuat, karena tujuan utama pilihan situs WBD adalah pelestarian situs itu sendiri. Namun ternyata terbukti pertama bahwa dukungan untuk pelestarian Subak Jatiluwih sangat kuat dan kemudian berangsur-angsur menjadi lebih lemah. Tujuan penelitian untuk mengetahui dan memahami sekaligus menjelaskan implikasi pasang-surutnya dukungan para pihak terkait terhadap pelestarian lingkungan alam dan budaya lokal di kawasan Subak 
Jatiluwih sebagai WBD, baik dalam kehidupan para pihak terkait maupun dalam pengelolaan kawasan subak tersebut sebagai warisan budaya dunia.

\section{Metodelogi Penelitian}

Penelitian ini menggunakan metode kualitatif, dengan mengikuti prosedur penelitian ilmu sosial, yaitu: pengumpulkan data dilakukan dengan wawancara, observasi, dan studi pustaka. Data yang terkumpul dianalisis, diverifikasi (display data) dan disimpulkan dalam narasi, table, foto, bagan dalam perspektif cultural studies. Teori yang digunakan dalam penelitian ini, yaitu teori ekologi manusia, teori sosiokultural, teori dekonstruksi, dan teori praktis.

\section{Pembahasan}

Kabupaten Tabanan dikenal sebagai "lumbung" berasnya Bali. Luas lahan pertanian dengan sistem subaknya yang terkenal ke seluruh dunia, menyebabkan Kabupaten Tabanan dalam hal ini kawasan Subak Jatiluwih mendapat perhatian dari masyarakat dunia. Konsep Hindu tentang Tri Hita Karana menjadi referensi penting akan adanya pengentalan Budaya Hindu di Bali. Bahkan, dari sudut pandang warisan budaya, daerah Tabanan yang kental dengan organisasi subaknya sebenarnya diperkaya dengan pemahaman ajaran Agama Hindu sebagaimana dapat dilihat dalam tradisi kehidupan masyarakat sebagaimana tercermin dalam sistem subak.

\section{Pengertian tentang Implikasi}

Implikasi dapat diartikan sebagai keterlibatan atau keadaan terlibat; yang termasuk atau tersimpul; yang disugestikan, tetapi tidak dinyatakan. Berimplikasi berarti mempunyai hubungan implikasi; 
mempunyai hubungan keterlibatan. Dalam pengertian umum, implikasi berarti sesuatu yang terlibat dalam suatu masalah.

Dalam kaitan dengan keberadaan kawasan subak Jatiluwih yang sudah diakui sebagai salah satu Warisan Budaya Dunia (WBD) yang dikenal sebagai World Cultural Heritage) tampaknya diperlukan sebuah komitmen bersama antara pemerintah, pengusaha di kawasan wisata, dan masyarakat Jatiluwih sendiri secara bersinergi.

Dalam kaitan ini sangat penting untuk dipahami bagaimana bentuk pengakuan pada penanda-penanda identitas budaya yang melekat pada kehidupan masyarakat di Jatiluwih yang memiliki posisi tawar, sehingga badan dunia seperti UNESCO (United Nations Educational, Scientific and Cultural Organization) memberikan pengakuan pada eksistensi atau keberadaan WBD di Jatiluwih. Branding yang berkaitan dengan subak misalnya adanya nilai-nilai atau makna yang terkandung dalam sistem subak sebagai bentuk organisasi pengairan pada lahan sawah yang disebut dengan konsep Tri Hita Karana yang sudah menjadi konsep yang mendunia ketika berbicara tentang pembangunan pertanian yang berkelanjutan yaitu adanya relasi yang harmonis antara manusia dengan Tuhan (parahyangan), manusia dengan manusia (pawongan) dan relasi antara manusia dengan lingkungannya (palemahan).

\section{Kebijakan Dari Atas ("Top Down Policy")}

Salah satu bentuk keinginan daerah mendapat penghargaan dari pemerintah pusat atau dari badan internasional yaitu dengan mengajukan usulan agar wilayah yang dijadikan kawasan wisata dapat mempertahankan karakter daerahnya yang berbasiskan pertanian. Benturan kepentingan ini tentu akhirnya bermuara pada berbagai konflik kepentingan tidak hanya yang bersifat vertikal, tetapi juga horisontal di kalangan masyarakat lokal di Jatiluwih. Untuk itu, menjadi beralasan 
apabila badan dunia yang membawahi masalah perlindungan pada ekosistem lingkungan yang berkelanjutan memiliki program pemeliharaan yang disebut dengan warisan budaya dunia. Program perlindungan inilah yang dipromosikan terutama di kalangan kawasan wisata yang diterngarai akan merubah paradigma masyarakat yang dahulunya bergerak di bidang pertanian akan bergeser ke aktifitas yang berkaitan dengan peningkatan kawasan wisata.

Kesepakatan untuk mengajukan usulan menjadi anggota WBD tidak seharusnya berdasarkan kebijakan yang berasal dari atas (top down policy), melainkan semestinya diusulkan dari bawah ke atas (bottom up policy). Kesadaran untuk pengajuan itu memang berasal dari bawah dengan memenuhi kriteria yang diperlukan dan apabila sudah memenuhi persyaratan kemudian diajukan ke UNESCO. Kebijakan politik dari pemerintah daerah akan memudahkan realisasi menjadi anggota WBD, yang hendaknya melihat kesiapan pada sistem kelembagaan dan tata kelola, apabila sudah disetujui menjadi anggota pusaka.

Menurut Nika Naya seorang mantan Kepala Dinas Kebudayaan Propinsi Bali yang sudah pensiun pada tahun 2008, menyebutkan bahwa usulan WBD Jatiluwih kalau dilihat sejarah pengusulannya berasal dari keluarnya instruksi Direktur Jenderal Pendidikan Tinggi cq Kepurbakalaan di Jakarta kepada pemerintah Provinsi Bali yang sudah dimulai sejak tahun 2001. Berdasarkan informasi dan dokumen yang ada, hal itu ditindaklanjuti dengan rapat yang diadakan pada tanggal 28 Juli 2002. Rapat itu dihadiri oleh Kepala Desa Jatiluwih, I Made Sumerjaya, sekretaris desa, para Kelihan Dinas, dan anggota BPD Jatiluwih. Saat itu diputuskan bahwa peserta rapat yang menghadiri rapat itu menyetujui agar Subak Jatiluwih diusulkan menjadi WBD.

Hasil rapat itu kemudian ditindaklanjuti dengan diadakannya lagi rapat pada tanggal 23 September 2002. Rapat itu dihadiri perwakilan 
berbagai instansi di Kabupaten Tabanan. Hasil rapat itu memberikan keputusan bahwa: Pertama, usulan agar dibuat Surat Keputusan Bupati Tabanan berkenaan dengan penunjukkan Subak Jatiluwih agar dimasukkan sebagai usulan WBD; Kedua, agar dibuat Surat Keputusan Bupati Tabanan tentang Penunjukan Penyusun Master Plan Subak Jatiluwih.

\section{Dilema Kebijakan "Top Down Policy"}

Dari penjelasan sebelumnya dapat dipahami bahwa, kebijakan untuk mengangkat kawasan subak Jatiluwih sebagai WBD, tampaknya bersifat Top Down Policy. Ini artinya kebijakan yang bersifat dari atas menghadapi dilema ketika diimplementasikannya kebijakan itu di lapangan. Ini disebabkan konsep yang dikemukakan oleh UNESCO bahwa sebuah kawasan WBD itu hendaknya melalui proses yang berasal dari bawah bottom up, adanya keinginan dan komitmen kuat dari warga masyarakatnya termasuk pengusaha yang memiliki kegiatan kawasan itu dan didukung secara kuat oleh pemerintah daerahnya. Perlu ada kesamaan pemahaman tentang sebuah kawasan menjadi WBD. Dalam konteks ini konsep warisan atau heritage dimaknai sebagai:

Heritage is the full range of our inherited traditions, monuments, objects, and culture. Most important, it is the range of contemporary activities, meanings, and behaviors that we draw from them. (Lihat: https://www.umass.edu/chs/about/whatisheritage.html).

Dengan demikian konsep warisan itu termasuk masalah perawatan, penggalian dari koleksi yang ada dan termasuk tinggalantinggalan yang ada di sekitar kawasan subak di Jatiluwih. Ini termasuk keduanya yaitu budaya materi (tangible culture) dan tak benda (intangible culture).

Ciri alam yang terdiri dari formasi fisik dan biologi atau kelompok dari formasi tersebut, yang memiliki nilai-nilai keunggulan sejagat dari 
sudut pandang estetika dan pengetahuan. Ini dimaksudkan bahwa kawasan subak Jatiluwih terkandung makna bahwa kawasan itu memiliki nilai-nilai adiluhung yang bersifat sejagat (outstanding universal value) ada pemahaman tentang adanya kehidupan harmonis yang berlandaskan ajaran Tri Hita Karana yang dapat disumbangkan konsep pemahaman ini kepada dunia atau kawasan lainnya dalam konteks pemeliharaan alam lingkungan yang mulai mendapat ancaman dari modernisasi dan globalisasi.

Terdapat tiga fokus permasalahan yang perlu digali yaitu: Pertama, identifikasi kekayaan budaya yang mencakup situs kesejarahan dan arkeologi dengan memusatkan perhatian pada peranan lembaga tradisional dan modern yang memiliki landasan peraturan yang resmi seperti Peraturan Daerah (PERDA), kualitas sumber daya manusia, dukungan masyarakat dan fasilitas yang memadai. Tahapan ini dianalisis berkaitan dengan konsep warisan alam dan budaya, kelembagaannya, orientasi nilai, filosofi yang mendasarinya, kebudayaan tradisional dan keberagamannya dan makna warisan budaya dalam konteks budaya fisik dan non-fisik, dan lanskap budaya masyarakatnya. Yang kedua, konservasi atau perlindungan kawasan subak Jatiluwih yang mencakup aksi komprehensif masyarakat, yang didasari pada studi teknologi dan terapan untuk mempertahankan kawasan warisan budaya Jatiluwih itu secara sistematis dan komprehensif. Ketiga, komodifikasi yang mencakup pengelolaan WBD Jatiluwih yang bersinergi dengan lembaga-lembaga lokal di masyarakat di Jatiluwih seperti dengan masyarakat adat atau desa pekraman, multi-SKPD (Satuan Kerja Perangkat Daerah), masyarakat dan pemerintah pusat (Kementerian Pertanian, Kementerian Pekerjaan Umum, Kementerian Kebudayaan dan Pariwisata), lembaga internasional seperti UNESCO. Dengan hal ini dimaksudkan untuk mengkomodifikasikan agar dapat memberikan kontribusi tidak hanya di tingkat lokal di masyarakat Jatiluwih tetapi juga bagi bangsa dan masyarakat internasional. 
Permasalahan inilah yang sebenarnya merupakan dilema ketika kebijakan yang berasal dari atas diarahkan untuk diaplikasikan di masyarakat Jatiluwih. Tampak proses pengusulan itu sebaiknya dari tingkatan paling bawah dari masyarakat. Untuk itu perlu kajian-kajian yang dilakukan yang dikawal oleh kelompok ahli kebudayaan yang hendaknya dimiliki oleh setiap pemerintah daerah. Ini dimaksudkan, jika kelompok ahli kebudayaan sudah dibentuk yang berada di bawah pengawasan bupati setempat maka kajian-kajian tentang berbagai potensi termasuk tata kelola WBD itu akan dapat dilakukan secara berkelanjutan dan terarah.

\section{Minimnya Kebijakan "Bottom Up"}

Berdasarkan hasil rapat, maka pada akhirnya dibuatlah Penerbitan Surat Keputusan Bupati Tabanan, Nomor: 590 Tahun 2002 pada tanggal 23 September 2002, yang isinya tentang Penunjukan Subak Jatiluwih untuk dimasukkan sebagai usulan WBD. Dengan dikeluarkannya Surat Keputusan ini dimaksudkan agar memperoleh dukungan pemerintah dan masyarakat internasional. Adapun Surat Keputusan yang berikutnya adalah dengan Penerbitan SK Bupati Tabanan Nomor: 623, Tahun 2002 pada tanggal 7 Oktober 2002 tentang Penunjukan Penyusun Master Plan Subak Jatiluwih. Dengan berdasarkan payung hukum atau regulasi inilah dikawal tentang bagaimana usulan itu diajukan ke UNESCO.

Selanjutnya rapat sosialisasi diselenggarakan pada tanggal 27 Nopember 2002 berkaitan dengan zona Subak Jatiluwih untuk diusulkan menjadi WBD, kemudian pimpinan pemerintah propinsi dalam hal ini Gubernur Bali mengantisipasi dan mencoba memfasilitasi perkembangan yang terjadi di daerah Tabanan berkaitan dengan keinginan untuk mengajukan usulan untuk Jatiluwih sebagai WBD. Untuk itu, tim kepanitiaan yang dipimpin oleh I Gde Parimartha mengadakan rapat di 
Kantor Gubernur Bali pada tanggal 17 Januari 2003 untuk membahas usulan yang diajukan pemerintah kabupaten Tabanan yang ditingkatkan usulan itu ke tingkat pemerintah Propinsi Bali, pada tahun 2003.

Muncul beberapa persoalan sekitar kehadiran surat keputusan gubernur tersebut diantara pertanyaan yang muncul adalah sekitar keberadaan Peraturan Gubernur Bali Nomor: 32 Tahun 2010 tentang Dewan Pengelola Warisan Budaya Bali, kegiatan-kegiatan yang dilakukan oleh personel yang ditetapkan dengan Peraturan Gubernur Bali Nomor 32 Tahun 2010 berkaitan dengan Dewan Pengelola Warisan Budaya Bali, dan kegiatan yang dilakukan oleh personel yang ditetapkan dengan Peraturan Gubernur Bali Nomor 1110/ 03-H/HK/20011 tentang Pembentukan dan Susunan Keanggotaan Dewan Pengelola Warisan Budaya Bali.

Setelah tahun 2002 tidak ditemukan adanya dokumen tentang kegiatan-kegiatan yang terkait dengan usulan Jatiluwih sebagai WBD yang sampai berlanjut hingga tahun 2011. Oleh karena itu, dikeluarkanlah Surat Keputusan Gubernur tentang pembentukan Dewan Pengelola Warisan Budaya Dunia Bali pada tahun 2011. Surat Keputusan yang bernomor Nomor 32 Tahun 2010 Dewan Pengelola Warisan Budaya Bali tampak belum ada atau diaplikasi dan personalia yang tertera di sana juga tidak banyak memunculkan aktifitasnya yang ditengarai dapat menjadi penyebab terjadinya pasang surut dukungan pada kawasan Subak Jatiluwih sebagai WBD.

Perkembangan terjadi pada tahun 2011, dimana terdapat penerbitan Keputusan Gubernur Bali Nomor: 1110/03-H/HK/20011 pada tanggal 28 Juli 2011 tentang Pembentukan dan Susunan Keanggotaan Dewan Pengelola Warisan Budaya Bali. Kemudian pada tanggal 29 September 2011 diikuti dengan telah terbitnya Peraturan Bupati Tabanan Nomor 35 Tahun 2011 tentang Dewan Pengelola Warisan Budaya Tabanan. 
Adanya ketidakjelasan kegiatan dalam kaitan dengan komitmen yang tegas, justru menimbulkan beberapa riak-riak di kalangan masyarakat. Misalnya adanya kegiatan pembolduseran pada kawasan WBD Jatiluwih yang ditengarai dapat menjadi indikator atau pertanda akan surutnya dukungan terhadap WBD Jatiluwih. Berkaitan dengan masalah pasang surut ini, tampaknya kemudian dikeluarkan Surat Edaran Bupati Tabanan tentang Pengendalian Pembangunan pada kawasan WBD Jatiluwih. Namun demikian, di lapangan pelaksanaan pemblodoseran tanah-tanah di kawasan tampak masih berlanjut dilakukan.

Akhirnya diterbitkanlah Keputusan Gubernur Bali Nomor: 11/ HK/ 2014 tentang Forum Kordinasi Pengelolaan Warisan Budaya Dunia Lansekap Budaya Provinsi Bali, namun masih belum jelas pula tentang kegiatan yang dilakukan oleh masing-masing personel pada forum itu dalam menjalankan tugasnya masing-masing yang sudah ditetapkan dalam keputusan Gubernur Bali.

\section{Warisan Budaya Dunia dan Internasionalisasi}

Sebagaimana sudah diuraikan sebelumnya bahwa di samping dinamika yang terjadi di dalam negeri Indonesia atau Asia Tenggara pada umumnya, tampak dinamika di luar Asia Tenggara berpengaruh pada dinamika dalam negeri. Hal ini dapat dilihat pada Negara Rusia yang telah mengubah kebijakannya di Bosnia dan Yugoslavia pada akhir tahun 1980an dan pada awal tahun 1990-an.

Berkaitan dengan pengedepanan aspek warisan budaya ini, maka tiap wilayah baik kabupaten dan kota di Indonesia, tidak menghindari adanya persaingan dalam memperoleh pengakuan dari UNESCO. Tidak hanya di Indonesia persoalan ini menguat, tetapi juga di negara-negara di kawasan Asia Tenggara. Kota budaya internasional misalnya tercakup Kyoto Jepang, Hoi Anh Ancient Town Vietnam, Malaka, dan Georgetown 
Malaysia, serta Macau Cina. Ke empat kota tersebut telah ditetapkan sebagai World Heritage City oleh Unesco.

Menurut Yamashita (2013), UNESCO memberikan persyaratan bahwa sejak tahun 2001 berkaitan dengan WBD yang diajukan itu hendaknya mencakup nilai unggul sejagat (universal outstanding value) dalam kaitannya baik dengan budaya fisik dan non fisik. Dalam kaitannya dengan warisan budaya itu, tidak hanya mencakup musik tradisional, sastra, seni, tetapi juga kebudayaan materi sebagaimana dapat dilihat pada peninggalan arkeologi dan sejarah, termasuk dalam kaitan ini berkaitan dengan tinggalan subak yang ada di Jatiluwih. Kekayaan tradisi budaya di Bali menyebabkan beberapa upaya untuk menjadikan permasalahan budaya dan seni maupun lingkungan sebagai sebuah WBD.

\section{Peran Pemerintah dalam Kaitannya dengan Pasang Surutnya Dukungan}

Dalam kaitannya dengan masalah pengusulan kawasan Jatiluwih ini dapat dikelompokkan adanya dua kelompok yang tampaknya saling kontroversial. Di satu pihak, terdapat pihak masyarakat lokal dan di pihak lainnya, terdapat pihak pemerintah daerah. Dukungan masing-masing pihak ini terlihat dari perannya dalam proses pengusulan Subak Jatiluwih sebagai WBD. Berikut dibahas peran pemerintah yang dianggap berperan penting terhadap terjadinya pasang surut dukungan kawasan Jatiluwih sebagai WBD itu.

Sejak semula pemerintah daerah, dalam hal ini Pemerintah Provinsi Bali sudah memberikan kontribusinya dalam proses pengusulan Subak Jatiluwih untuk dijadikan WBD. Hal ini dapat ditelusuri dengan dikeluarkannya Keputusan Gubernur Bali Nomor: 1110/03-H/HK/2011 tentang Pembentukan dan Susunan Keanggotaan Dewan Pengelola Warisan Budaya Bali. Keputusan Gubernur Bali ini terlihat sangat 
signifikan. Dalam kaitan ini, karena di dalamnya terdapat pernyataan yang menujukkan hubungan Keputusan Gubernur Bali ini dengan pengusulan warisan budaya Bali menjadi WBD. Pengusulan Subak Jatiluwih sebagai warisan budaya Bali yang sedang diusulkan untuk dijadikan WBD terjadi pada tahun 2011. Dalam kaitan ini kontribusi Pemerintah Provinsi Bali sangat signifikan dalam konteks pemajuan usulan itu. Hal ini didasari atas pernyataan-pernyataan yang disampaikan berkenaan dengan unsur-unsur dan tugas-tugas Dewan Pengelola Warisan Budaya Bali.

\section{Kesimpulan}

Pasang surutnya dukungan terhadap WBD Subak Jatiluwih mengimplikasikan hal-hal yang penting untuk dikritisi. Implikasinya itu adalah: (1) terjadinya kebijakan yang bersifat "top down" dalam pengusulan Subak Jatiluwih untuk dijadikan WBD serta dalam pengelolaannya setelah menjadi WBD; (2) terjadi proses penginternasionalisian Subak Jatiluwih hingga semakin terkenal di seluruh dunia.

\section{Temuan}

Temuan penelitian ini dapat dipilah menjadi dua macam. Pertama, bahwa peraturan yang sudah dinyatakan berlaku seperti Keputusan Gubernur, Keputusan Bupati, Peraturan Daerah tidak selalu terimplemtasi sebagaimana mestinya. Kedua, superstruktur ideologi tidak selalu menjadi pedoman yang menentukan struktur sosial dan infrastruktur sebagaimana diasumsikan dalam teori sosiokultural menurut Sanderson. 


\section{Daftar Pustaka}

Hadi Sudharto P. 2000. Manusia dan Lingkungan. Semarang: Badan Penerbit Universitas Diponegoro.

Irawan Prasetya. 2006. Metode Penelitian Kualitatif \& Kuantitatif untuk Ilmuilmu Sosial. Jakarta: Penerbit universitas Indonesia.

Lubis Akhyar Yusuf. 2006. Dekonstruksi Epistimologi Modern dari Posmodernisme Teori Kritis Poskolonialisme Hingga Kultural Studies. Jakarta: Pustaka Indonesia Satu.

Kaler, I Gusti Ketut. 1985. Tinjauan Sosial Budaya. Bahan ceramah di depan para anggota Himpunan Ahli Teknik Hidraulik Indonesia Cabang Bali, tanggal 16 September 1985 di Denpasar.

Suriasumantri, Jujun S. 1984. Filsafat Ilmu Pengetahuan. Jakarta: Penerbit Sinar Harapan

Takwin, Bagus. 2003. Akar-Akar Ideologi: Pengantar Kajian Konsep Ideologi dari Plato Hingga Bourdieu. Yogyakarta: Jalasutra

Yamashita, Shinji. 2014. "The Balinese Subak as World Cultural Heritage", dalam Jurnal Kajian Bali Vol. 3. Nomor: 2, 2013.

\section{Sumber Undang-Undang dan Peraturan Pemerintah}

Keputusan Gubernur Bali No.1110/03-H/HK/2011 Tentang Pembentukan dan Susunan Keanggotaan Dewan Pengelola Warisan Budaya Bali.

Peraturan Bupati Tabanan No. 9 Tahun 2005 Tentang RDTR. Kawasan Pelestarian Alam dan Budaya Jatiluwih.

Peraturan Bupati Tabanan No. 27 Tahun 2011 Tentang Penetapan Sawah Berkelanjutan Sebagai Sawah Abadi Pada Subak Di Kecamatan Penebel, Kabupaten Tabanan.

Surat Edaran Bupati Tabanan No. 050/0221/Bappeda Tentang Pengendalian Pembangunan Pada Kawasan WBD Jatiluwih.

Surat Undangan Hubert Gijzen, Director and Representative UNESCO Office Jakarta kepada Bupati Tabanan, tanggal 13 Juni 2012 tentang "Invitation to Lunch reception and Press Conference at the Jatiluwih Rice Terrace, Bali, 25 Juni 2012". 
I Gede Susila

58 JOURNEY Volume 1 Nomor 2 Juni 2019 